\title{
Identificação de genótipos de feijoeiro comum tolerantes ao alumínio
}

\section{Rodrigo Ribeiro Fidelis ${ }^{1}$, Patricia Sumara Moreira Fernandes ${ }^{1}$, Erica Rodrigues Moreira ${ }^{1}$, Taynar Coelho de Oliveira Tavares ${ }^{1}$}

\footnotetext{
${ }^{1}$ Universidade Federal do Tocantins, Campus Universitário de Gurupi, Gurupi, Tocantins, Brasil. E-mail: fidelisrr@uft.edu.br, patricia.sms@hotmail.com, ermoreira01@gmail.com, taynar@uft.edu.br
}

Recebido: 17/07/2017; Aceito: 29/07/2018.

\section{RESUMO}

Este trabalho teve como objetivo identificar genótipos de feijão comum tolerantes ao alumínio, em solução nutritiva. $\mathrm{O}$ experimento foi conduzido em condições de casa de vegetação, na Universidade Federal do Tocantins - Campus Universitário de Gurupi - TO, em blocos inteiramente casualizados, com seis repetições e tratamentos dispostos em esquema fatorial constituído por 15 genótipos e quatro tratamentos: 0,3 e $6 \mathrm{mg} \mathrm{L}^{-1}$ de alumínio em pH 4,0 $\pm 0,2$ e $0 \mathrm{mg} \mathrm{L}^{-1}$ de alumínio em pH 6,5 \pm 0,2. Foram avaliadas as seguintes características: comprimento da parte aérea, comprimento radicular, massa seca da parte aérea e massa seca radicular. Concluiu-se que existe variabilidade genética entre os genótipos de feijão comum quanto à tolerância ao alumínio. Os cultivares IPR Chopim e VC3 foram considerados tolerantes ao alumínio, apresentando bom desenvolvimento radicular. Com isso, a utilização desses genótipos em programas de melhoramento genético pode ser uma alternativa para a agricultura familiar, por possuírem características agronômicas desejáveis relacionadas à tolerância por alumínio.

Palavras-chave: Phaseolus vulgaris L., solos ácidos, estresse abiótico, toxicidade.

\section{Identification of common bean genotypes tolerant to aluminum}

\begin{abstract}
This work was objective identify common bean genotypes tolerant to aluminum in nutrient solution. The experiment was conducted under greenhouse conditions, at Federal University of Tocantins - Campus de Gurupi TO, in completely randomized blocks, with six replicates and treatments arranged in a factorial scheme, consisting of 15 genotypes and four treatments: 0,3 and $6 \mathrm{mg} \mathrm{L}^{-1}$ aluminum at $\mathrm{pH} 4.0 \pm 0.2$ and $0 \mathrm{mg} \mathrm{L}^{-1}$ aluminum at $\mathrm{pH} 6.5 \pm 0.2$. The shoot length, root length, dry shoot mass and root dry mass were measured. It is concluded that there is genetic variability among common bean genotypes regarding tolerance to aluminum. The cultivars IPR Chopim and VC3 were considered tolerant to aluminum presenting good root development. Therefore, the use of these genotypes in breeding programs may be an alternative to family farming, because they have desirable agronomic characteristics related to aluminum tolerance.
\end{abstract}

Keywords: Phaseolus vulgaris L., acid soils, abiotic stress, toxicity. 


\section{Introdução}

O feijão é uma das principais leguminosas presentes na dieta dos brasileiros e ocupa lugar essencial na alimentação humana, principalmente por possuir elevados teores de proteína e complementa nutricionalmente outros alimentos como o arroz (Lopes Junior et al., 2010).

É inquestionável a importância do feijão na alimentação e na economia da população brasileira. Grande parte da produção é obtida por pequenos agricultores que não usam alta tecnologia e retiram parte da produção para o seu sustento, vendendo o excedente, o que contribui para que seja uma cultura estigmatizada como pouco competitiva.

O ministério da agricultura divulgou uma projeção de produção e área plantada onde na safra 2016/2017 serão produzidos 3,3 milhões de toneladas de feijão, com área plantada de 2,9 milhões de hectares (Brasil/Mapa, 2015). O Estado do Tocantins participa da produção de feijão apenas na safra e safrinha, desde a década de 70, sendo o único produtor na safra das águas dentro da Região Norte (Conab, 2013). Na safra de 2016/2017, a produtividade média alcançada no Estado foi de $1.383 \mathrm{~kg} \mathrm{ha}^{-1}$, com área plantada de 7,0 mil hectares (Conab, 2017).

A maior parte do território tocantinense é constituída pelo bioma Cerrado, sendo este pobre em nutrientes, mas rico em ferro e alumínio. O solo ácido é um dos principais responsáveis pela baixa produtividade das culturas, constituindo fator limitante ao crescimento das plantas. Em condições ácidas, o Al é liberado para a solução do solo na sua forma iónica, que é tóxico para o crescimento das plantas. O sintoma característico da toxicidade do $\mathrm{Al}$ é a inibição do alongamento da raiz (Huang et al., 2009). Por ser acumulado nas raízes, retarda seu crescimento e desenvolvimento, aumentando seu diâmetro e reduzindo o número de raízes laterais, as principais responsáveis pela absorção de nutrientes e água (Mattiello et al., 2008).

Muitas espécies vegetais apresentam mecanismos de tolerância à toxidez por alumínio, que são controlados genética e/ou fisiologicamente, possuindo a capacidade de tolerar altas concentrações desse metal devido à sua complexação com ácidos orgânicos exsudados pelo sistema radicular e ao genótipo vegetal, que pode promover a capacidade de se adequar a condições físico-químicas adversas, minimizando os problemas causados pela baixa produtividade em solos ácidos (Nolla et al., 2007).

A seleção de plantas que suportam vários níveis de alumínio vem sendo considerada a melhor alternativa para o aumento da produção em solos ácidos, com concentrações altas desse cátion (Martins et al., 2011). Práticas envolvendo diferentes métodos estão sendo empregadas tanto em cultura de campo como em soluções nutritivas (Sanchez-Chacón et al., 2002). Com isso, é importante determinar a tolerância ao Al dos genótipos disponibilizados aos agricultores para que este possa ser um aspecto a ser considerado quanto à escolha do cultivar (Hervé et al., 2013).

Constituições genotípicas superiores que proporcionam melhor ajuste a condições nutricionais adversas poderão amenizar os problemas de produtividade em solos ácidos, ocasionados pelo estresse causado pelo alumínio (Freitas et al., 2006).

Neste contexto, o presente trabalho teve como objetivo avaliar a tolerância e identificar os genótipos de feijão comum pertencentes ao grupo carioca e preto, submetidos a diferentes doses de alumínio.

\section{Material e Métodos}

O experimento foi conduzido em condições de casa de vegetação, na Universidade Federal do Tocantins Campus Universitário de Gurupi - TO $\left(11^{\circ} 43^{\prime} 45^{\prime \prime} \mathrm{S}\right.$ e $49^{\circ} 04^{\prime} 07^{\prime \prime} \mathrm{W}$, e $280 \mathrm{~m}$ de altitude). O clima regional é do tipo B1wA'a' úmido, com moderada deficiência hídrica (Köppen, 1948).

O delineamento experimental foi de blocos inteiramente casualizados em esquema fatorial $15 \times 4$ com seis repetições, sendo cada repetição representada por uma planta. As concentrações foram $0 \mathrm{mg} \mathrm{L}^{-1} \mathrm{de}$ alumínio em pH $6,5 \pm 0,2 ; 0 \mathrm{mg} \mathrm{L}^{-1}$ de alumínio em $\mathrm{pH}$

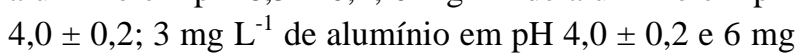
$\mathrm{L}^{-1}$ de alumínio em $\mathrm{pH} 4,0 \pm 0,2$. A fonte de $\mathrm{Al}^{3+}$ utilizada foi o sulfato de alumínio $\left(\mathrm{Al}_{2}\left(\mathrm{SO}_{4}\right)_{3} .18 \mathrm{H}_{2} \mathrm{O}\right)$.

Os genótipos de feijão comum avaliados em sistema hidropônico são pertencentes aos grupos carioca (IAC Alvorada, IPR Colibri, IPR Juriti, BRS Requinte, IPR Siriri, Pontal, BRS Aporé, CNFC 10406, VC3, IPR Eldorado, CNFC 10467, e IAC Eté), mulatinho (IAC Centauro), pintado (IPR Corujinha) e preto (IPR Chopim). O mesmo experimento foi dividido em duas baterias, a primeira envolvendo oito genótipos, e, a segunda, sete genótipos, quatro tratamentos e seis repetições por um período de 20 dias.

Foram selecionadas 100 sementes de cada cultivar, sendo estas tratadas com inseticidas (tiametoxame, clorantraniliprole + lambdacialotrina $-300 \mathrm{~mL}$ p.c. 100 $\mathrm{kg}^{-1}$ de sementes) e fungicidas (carbendazim + thiram $300 \mathrm{~mL}$ p.c. $100 \mathrm{~kg}^{-1}$ de semente). As sementes foram colocadas para germinar durante cinco dias em rolos de papel germitest umedecidos com água destilada na proporção de 2,5 vezes o peso do papel seco, num total de 50 sementes por rolo (Brasil, 2009). No período de germinação, os rolos foram mantidos verticalmente com regime luminoso integral, temperatura ambiente e molhados duas vezes ao dia, mantendo-se a umidade.

Utilizou-se plântulas normais e com tamanho uniforme em relação à emissão da radícula (Brasil, 
2009) de cada cultivar, sendo transplantadas para bandejas de $60 \times 20 \times 10 \mathrm{~cm}$, com capacidade para 12 litros, contendo solução nutritiva de Hoagland e Arnon (1950) diluída a $1 / 2$ de concentração iônica: $2.5 \mathrm{mM}$ $\mathrm{KNO}_{3} ; 2 \mathrm{mM} \mathrm{MgSO}{ }_{4} ; 1 \mathrm{mM} \mathrm{KH}_{2} \mathrm{PO}_{4} ; 2.5 \mathrm{mM}$ $\mathrm{Ca}\left(\mathrm{NO}_{3}\right)_{2} ; 4.6 \mu \mathrm{M} \mathrm{MnCl}{ }_{2} ; 23.2 \mu \mathrm{M} \mathrm{H}_{3} \mathrm{BO}_{3} ; 0.06 \mu \mathrm{M}$ $\mathrm{Na}_{2} \mathrm{MoO}_{4} ; 0.4 \mu \mathrm{M} \mathrm{ZnSO}_{4} ; 0.19 \mu \mathrm{MCuSO}_{4}$ e $2,5 \mathrm{mg} \mathrm{L}$ ${ }^{1}$ de Fe (Fe-EDTA).

Para suportar as plântulas, foram utilizadas placas de isopor revestidas com papel alumínio e algodão. Após quatro dias em solução nutritiva completa, a solução foi trocada, colocando-se uma nova solução sem o fósforo, e o alumínio foi acrescentado ao meio. $\mathrm{O} \mathrm{pH}$ foi ajustado com o auxílio de um pHmetro para 4,0 $\pm 0,2$ e $6,5 \pm 0,2$ (o ajuste foi realizado diariamente), de acordo com os tratamentos, utilizando uma solução de ácido clorídrico $(\mathrm{HCl})$ a $0,1 \mathrm{~N}$, onde as plântulas foram mantidas por oito dias. A aeração da solução nutritiva foi feita com bombas de aeração de aquário, as quais foram mantidas funcionando initerruptamente após o transplantio.

Em intervalos de três dias, realizou-se um rodízio no posicionamento das bandejas nas bancadas para assegurar a homogeneidade das condições ambientais.

Ao final do experimento, avaliou-se as seguintes características: o comprimento radicular $(\mathrm{CR}) \mathrm{em} \mathrm{cm}$, considerando a raiz de maior tamanho a partir do coleto, por meio de medição direta com o auxílio de uma régua graduada; a altura da planta (AP) em cm, medida efetuada do colo da planta à extremidade da folha mais alta; massa seca das raízes (MSR) e massa seca da parte aérea (MSP), determinadas pela pesagem das raízes e das partes aéreas após terem sido secas em estufa de ventilação forçada, a $60^{\circ} \mathrm{C}$, até peso constante por um período de 72 horas; e o índice de Redução (IR), modificado para a característica $\mathrm{CR}$ e calculado pela seguinte expressão:

$\operatorname{IR}(\%)=\{[(\mathrm{CSA}-\mathrm{CCA}) / \mathrm{CSA}] \times 100\}$, sendo:

CSA - Comprimento de raiz avaliada no tratamento sem alumínio (0 $\mathrm{mg} \mathrm{L}^{-1}$ e pH 6,5);

CCA - Comprimento de raiz avaliada no tratamento com alumínio (6 mg L $\mathrm{m}^{-1}$ e $\left.\mathrm{pH} 4,0\right)$.

Com base no desempenho dos cultivares avaliados em relação ao comprimento radicular (CR), quando cultivados em solução nutritiva sem $\mathrm{Al}^{3^{+}}$e $\mathrm{pH}$ 6,5 e o índice de redução para esta característica, os genótipos foram classificados em quatro grupos: pouco tolerante à toxidez por alumínio e com alto desenvolvimento radicular (quadrante I); pouco tolerante ao alumínio e com baixo desenvolvimento radicular (quadrante II); tolerante à toxidez por alumínio e com baixo desenvolvimento radicular (quadrante III); e tolerante à toxidez de alumínio e com alto desenvolvimento radicular (quadrante IV).
Os dados foram submetidos à análise de variância e ao teste de Tukey para comparar as médias das concentrações e dos genótipos dentro de cada concentração, a 5\% de probabilidade, utilizando-se o aplicativo computacional SISVAR (Ferreira, 2011).

\section{Resultados e Discussão}

A análise de variância (Tabela 1) mostrou efeito significativo para a interação entre tratamento e cultivares para a maioria das características em estudo, mostrando que as concentrações influenciaram no comportamento dos cultivares, sendo, portanto, necessário efetuar o desdobramento dos fatores. Os fatores genótipos e concentrações apresentaram significância para as características estudadas, revelando que existe variabilidade entre genótipos, bem como diferença entre as concentrações.

Para a característica comprimento da parte aérea (Tabela 2) não houve diferença significativa entre os genótipos na concentração $6 \mathrm{mg} \mathrm{L}^{-1} \mathrm{de} \mathrm{Al}^{3^{+}}$em pH 4,0. $\mathrm{Na}$ concentração de $3 \mathrm{mg} \mathrm{L}^{-1}$ de $\mathrm{Al}^{3^{+}}$em $\mathrm{pH} 4,0$, o genótipo Colibri obteve maior média $(46,08 \mathrm{~cm})$, diferindo significativamente de todos genótipos, exceto do IPR-Corujinha $(40,30 \mathrm{~cm})$. Para o tratamento sem adição de $\mathrm{Al}^{3^{+}}$em $\mathrm{pH}$ 4,0 houve diferença significativa entre o IPR Corujinha $(32,88 \mathrm{~cm})$, o Pontal $(21,77 \mathrm{~cm})$ e o IPR Siriri $(20,17 \mathrm{~cm})$. Já no tratamento sem $\mathrm{Al}^{3+} \mathrm{em}$ $\mathrm{pH} 6,5$, o genótipo IPR Corujinha diferiu significativamente entre os genótipos IPR Eldorado e IPR Siriri, obtendo maior média $(35,28 \mathrm{~cm})$. Quanto ao efeito da concentração, observa-se que apenas para o Colibri houve diferença entre as médias de concentração, sendo maior $(46,08 \mathrm{~cm})$ na dose de $3 \mathrm{mg}$ $\mathrm{L}^{-1}$ de $\mathrm{Al}^{3^{+}}$em $\mathrm{pH} 4,0$.

Estes resultados se opõem aos encontrados por Bresolin et al. (2012), onde, trabalhando com Azévem, observaram reduções sucessivas com o aumento nas doses de $\mathrm{Al}\left(0 \mathrm{mg} \mathrm{L}^{-1}, 7 \mathrm{mg} \mathrm{L}^{-1}\right.$ e $\left.21 \mathrm{mg} \mathrm{L}^{-1}\right)$, com exceção da população CNPGL188, que manteve o CPA inalterado com o aumento do nível de estresse.

Quanto à característica comprimento radicular (Tabela 3), houve diferença significativa para a interação genótipo e concentração quando se utilizou a maior concentração de $\mathrm{Al}^{3^{+}}\left(6 \mathrm{mg} \mathrm{L}^{-1}\right.$ de $\mathrm{Al}^{3^{+}}$em $\mathrm{pH}$ $4,0)$ para os genótipos IPR Corujinha $(15,50 \mathrm{~cm}) \mathrm{e}$ Chopim $(24,80 \mathrm{~cm})$, sendo que o último apresentou maior média de raiz. Já na concentração de $3 \mathrm{mg} \mathrm{L}^{-1}$ de $\mathrm{Al}^{3^{+}}$em pH 4,0 não houve diferença significativa entre os genótipos. Para o tratamento sem alumínio $\left(0 \mathrm{mg} \mathrm{L}^{-1}\right.$ de $\mathrm{Al}^{+3}$ em $\mathrm{pH} 4,0$ ), a maior média foi obtida pelo genótipo Eldorado $(34,05 \mathrm{~cm}), \quad$ diferindo estatisticamente do VC3 $(25,34 \mathrm{~cm})$, do IPR-Siriri $(22,58 \mathrm{~cm})$ e do CNFC $10406(23,28 \mathrm{~cm})$. 
Tabela 1. Análise de variância para comprimento de parte aérea (CP), comprimento de raiz (CR), massa seca de parte aérea (MSA) e massa seca de raiz (MSR) em 15 genótipos de feijão comum cultivados na região sul do Estado do Tocantins - Gurupi, TO.

\begin{tabular}{llcccc}
\hline F.V. & \multicolumn{3}{c}{ Q M } \\
\hline & GL & CP & CR & MAS & MSR \\
Genótipo & 14 & $237,07^{* *}$ & $46,23^{*}$ & $0,147^{* *}$ & $0,009^{* * *}$ \\
Concentração & 3 & $175,46^{* *}$ & $1310,46^{* *}$ & $0,483^{* *}$ & $0,004^{\text {NS }}$ \\
Genótipo x Concentração & 42 & $56,16^{* *}$ & $48.81^{* *}$ & $0,055^{* *}$ & $0,006^{* *}$ \\
Repetição & 5 & $80,45^{\mathrm{NS}}$ & $3,05^{\mathrm{NS}}$ & $0,013^{\mathrm{NS}}$ & $0,004^{\mathrm{NS}}$ \\
CV\% & & 19,85 & 17,40 & 30,18 & 50,09 \\
\hline Média Geral & \multicolumn{2}{c}{26,68} & 25,08 & 0,395 & 0,112 \\
*significativo a 1\% pelo teste F* ** significativo a 5\% pelo teste F* ns - não significativo
\end{tabular}

*significativo a $1 \%$ pelo teste $\mathrm{F}$; ** significativo a $5 \%$ pelo teste $\mathrm{F}$; ns - não significativo.

Tabela 2. Média da característica comprimento da parte aérea de 15 genótipos de feijão comum cultivados em concentrações diferentes de alumínio a pH 4,0 $\pm 0,2\left(0,3\right.$ e $\left.6 \mathrm{mg} \mathrm{L}^{-1}\right)$ e a pH 6,5 $\pm 0,2 \mathrm{sem}$ alumínio, na região sul do Estado do Tocantins - Gurupi, TO.

\begin{tabular}{|c|c|c|c|c|}
\hline \multirow{3}{*}{ Genótipos } & \multicolumn{4}{|c|}{ Comprimento da parte aérea $(\mathrm{cm})$} \\
\hline & \multicolumn{3}{|c|}{$\mathrm{pH} 4,0$} & \multirow{2}{*}{$\begin{array}{c}\mathrm{pH} 6,5 \\
0 \mathrm{mg} \mathrm{L}^{-1}\end{array}$} \\
\hline & $0 \mathrm{mg} \mathrm{L}^{-1}$ & $3 \mathrm{mg} \mathrm{L}^{-1}$ & $6 \mathrm{mg} \mathrm{L}^{-1}$ & \\
\hline VC3 & $25,46 \mathrm{abA}$ & $25,92 \mathrm{Ca}$ & $24,42 \mathrm{aA}$ & $26,42 \mathrm{abA}$ \\
\hline Pontal & $21,77 \mathrm{bA}$ & $22,70 \mathrm{Ca}$ & $23,67 \mathrm{aA}$ & $25,15 \mathrm{abA}$ \\
\hline IPR Juriti & $24,52 \mathrm{abA}$ & $24,42 \mathrm{cA}$ & $23,08 \mathrm{aA}$ & $27,22 \mathrm{abA}$ \\
\hline IPR Corujinha & $32,88 \mathrm{aA}$ & $40,30 \mathrm{abA}$ & 33,33 aA & $35,38 \mathrm{aA}$ \\
\hline IPR Eldorado & $29,82 \mathrm{abA}$ & $26,83 \mathrm{Ca}$ & $28,42 \mathrm{aA}$ & $24,78 \mathrm{bA}$ \\
\hline IPR Colibri & $24,57 \mathrm{abB}$ & $46,08 \mathrm{aA}$ & $23,83 \mathrm{aB}$ & $29,98 \mathrm{abB}$ \\
\hline BRS Aporé & $24,93 \mathrm{abA}$ & $25,33 \mathrm{cA}$ & $26,33 \mathrm{aA}$ & $27,17 \mathrm{abA}$ \\
\hline IPR Siriri & $20,17 \mathrm{bA}$ & $22,83 \mathrm{cA}$ & $24,33 \mathrm{aA}$ & $24,08 \mathrm{bA}$ \\
\hline IAC Alvorada & $27,75 \mathrm{abA}$ & $23,82 \mathrm{cA}$ & $25,25 \mathrm{aA}$ & $25,23 \mathrm{abA}$ \\
\hline CNFC 10406 & $26,33 \mathrm{abA}$ & $27,20 \mathrm{cA}$ & $24,88 \mathrm{aA}$ & $25,67 \mathrm{abA}$ \\
\hline IPR Chopim & $28,20 \mathrm{abA}$ & $26,00 \mathrm{cA}$ & $25,10 \mathrm{aA}$ & $26,87 \mathrm{abA}$ \\
\hline IAC Centauro & $28,28 \mathrm{abA}$ & $31,70 \mathrm{bcA}$ & $26,92 \mathrm{aA}$ & $26,92 \mathrm{abA}$ \\
\hline BRS Requinte & $26,67 \mathrm{abA}$ & $27,66 \mathrm{cA}$ & $23,00 \mathrm{aA}$ & $28,50 \mathrm{abA}$ \\
\hline IAC Eté & $24,50 \mathrm{abA}$ & $28,97 \mathrm{cA}$ & $24,30 \mathrm{aA}$ & $26,25 \mathrm{abA}$ \\
\hline CNFC 10467 & $21,77 \mathrm{abA}$ & $27,80 \mathrm{cA}$ & $23,10 \mathrm{aA}$ & $25,20 \mathrm{abA}$ \\
\hline Média Geral & 25,90 & 28,50 & 25,33 & 26,99 \\
\hline
\end{tabular}

Médias seguidas de mesma letra minúscula na coluna e maiúscula na mesma linha não diferem entre si pelo teste Tukey, a $\%$ de probabilidade.

No tratamento sem alumínio em $\mathrm{pH}$ 6,5, a maior média foi do genótipo CNFC 10467, que diferiu do Alvorada, do Siriri, do Eldorado e do Juriti. Os genótipos IPR-Chopim, IPR-Siri, IPR-Juriti e Pontal não apresentaram diferenças significativas, independente dos tratamentos aplicados, porém, o restante deles diferiu significativamente, apresentando redução no comprimento das raízes quando foi utilizada a maior concentração de alumínio. Resultados semelhantes foram encontrados por Zeffa et al. (2011), que, trabalhando com cultivares e linhagens de feijão, observaram que as plantas, quando submetidas à concentração $10 \quad \mathrm{mg} \mathrm{L} \mathrm{L}^{-1}$ de alumínio, obtiveram diminuição do comprimento radicular. Sharma et al. (2011), em experimento de soja, verificaram que algumas raízes encolheram devido ao estresse ao $\mathrm{Al}$ e que o comprimento de raiz pode ser usado eficientemente na seleção de genótipos tolerantes a esse estresse.
Os genótipos que constituíram maiores médias de comprimento radicular podem ter obtido esses valores devido ao fato de que em meio ácido e na presença de alumínio a planta desenvolve mecanismos de tolerância, normalmente pela neutralização do íon, já que plantas tolerantes devem ser capazes de prevenir a absorção de alumínio (Cançado et al., 2001) ou de complexá-los após sua absorção (Parentoni et al., 2001).

Plantas tolerantes têm a garantia de um bom desenvolvimento do sistema radicular, o que permite a obtenção de nutrientes e água em maiores profundidades durante períodos secos, enquanto os cultivares sensíveis não sobreviveriam (Miguel et al., 2010). Desta forma, apresentariam potencial para plantio em solos ácidos, bem como a utilização em programas de melhoramento genético direcionados para obtenção de cultivares adaptados às condições de cerrado. 
Os genótipos que apresentaram as menores médias de comprimento radicular podem ser explicados em decorrência da inibição da expansão celular nas raízes, seguido pela inibição da divisão celular, provocando o desenvolvimento de raízes anatomicamente anormais quando as mesmas são expostas a altos níveis de concentração de alumínio trocável (Zeffa et al., 2011).

Após o período de análise, o tratamento na concentração de $\mathrm{Al}^{3+}\left(6 \mathrm{mg} \mathrm{L}^{-1}\right.$ e $\left.3 \mathrm{mg} \mathrm{L}^{-1}\right)$ visualmente apresentou alterações morfológicas, como raízes grossas de coloração acastanhada. A mesma alteração foi observada por Zeffa et al. (2011) trabalhando com feijão quanto à tolerância ao estresse de $\mathrm{Al}\left(0 \mathrm{e} 7 \mathrm{mg} \mathrm{L} \mathrm{L}^{-1}\right)$.

Em soluções ácidas, o $\mathrm{Al}$ acumula, tornando as raízes mais grossas, amareladas nas pontas, degeneradas, tortuosas, com ramificações secundárias, escuras, em parte pela oxidação de compostos fenólicos, e sem pelos absorventes. Além disso, quando expostas ao cátion, há desintegração dos tecidos da epiderme e de porções externas do córtex nos ápices das raízes, ficando as células enrugadas e, em casos de maior gravidade, colapsadas; há também redução no tamanho da coifa e desarranjo do tecido meristemático, além de formação de protoxilema e endoderme em regiões próximas ao ápice radicular com altos teores de lignina (Peixoto et al., 2007).

Com relação à massa seca da parte aérea (Tabela 4), houve diferença significativa para a maior concentração de alumínio $\left(6 \mathrm{mg} \mathrm{L}^{-1}\right)$ em pH 4,0 entre o genótipo IAC Alvorada $(0,620 \mathrm{~g})$ e os demais, exceto para CNFC $10406(0,427$ g), IAC Centauro $(0,477 \mathrm{~g})$, BRS Requinte $(0,446 \mathrm{~g})$, IAC Eté $(0,395 \mathrm{~g})$ e CNFC 10467 $(0,404 \mathrm{~g})$.

$\mathrm{Na}$ concentração $3 \mathrm{mg} \mathrm{L} \mathrm{L}^{-1} \mathrm{Al}^{3+}$ em pH 4,0, o genótipo com maior média $(0,581 \mathrm{~g})$ foi o BRSRequinte, que diferiu dos genótipos VC3 (0,229 g), Pontal (0,223 g), Juriti (0,289 g), Eldorado (0,226 g), Colibri (0,329 g), Siriri (0,153 g) e Chopim (0,312 g). Para o tratamento sem alumínio em $\mathrm{pH} 4,0$, houve diferença significativa entre o genótipo IAC Alvorada $(0,763$ g) e os demais genótipos, com exceção do Corujinha $(0,552 \mathrm{~g})$ e do IPR-Eldorado $(0,550 \mathrm{~g})$, grupo que constituiu maiores médias. Em pH 6,5 sem adição de alumínio, o genótipo IPR Chopim $(0,710$ g) obteve maior média, não diferindo dos genótipos BRS Aporé $(0,476 \mathrm{~g})$ e Requinte $(0,541 \mathrm{~g})$.

Em relação ao efeito da concentração, não houve diferença para os genótipos Pontal, IPR Juriti, CNF 10406, IAC Centauro, BRS Requinte, IAC Eté e CNF 10467. Os genótipos que diferiram com a mudança dos tratamentos apresentaram redução da MSPA com a adição de $\mathrm{Al}^{3+}$. Estes resultados corroboram com os encontrados por Nolla et al. (2007), onde, estudando plântulas de soja em função da atividade de alumínio na solução do solo, notaram que em $\mathrm{pH}$ baixo $(\mathrm{pH} 4,0)$ houve redução na matéria seca da parte aérea, com o aumento da concentração de alumínio na solução.

Considerando a característica massa seca radicular (Tabela 5) na concentração $6 \mathrm{mg} \mathrm{L}^{-1} \mathrm{em} \mathrm{pH} \mathrm{4,0,} \mathrm{houve}$ diferença significativa entre os genótipos CNF-10406 $(0,214 \mathrm{~g})$, Pontal (0,076 g), Chopim (0,084 g), Eté $(0,090 \mathrm{~g})$ e CNF-10467 (0,088 g), uma vez que CNF10406 (valor) obteve maior média para esta característica. Para a concentração $3 \mathrm{mg} \mathrm{L}^{-1}$ de $\mathrm{Al}^{3^{+}}$em pH 4,0, não houve diferença entre os genótipos, exceto entre Chopim (0,187 g) e CNF 10467 (0,075 g), apresentando uma maior média com o genótipo Chopim. No tratamento sem $\mathrm{Al}^{3^{+}}$em $\mathrm{pH}$ ácido não houve diferença significativa para a maioria dos genótipos, exceto Eldorado (0,171 g) e CNF 10467 $(0,010 \mathrm{~g})$, que diferiram entre si. Já no tratamento sem $\mathrm{Al}^{3+}$ em pH 6,5, não houve diferença significativa entre os genótipos. Segundo Zeffa et al. (2011), esses valores podem ser explicados pelo fato de raízes submetidas a níveis tóxicos de alumínio apresentarem o sistema radicular mais grosso, podendo, assim, aumentar a quantidade de matéria seca de raiz.

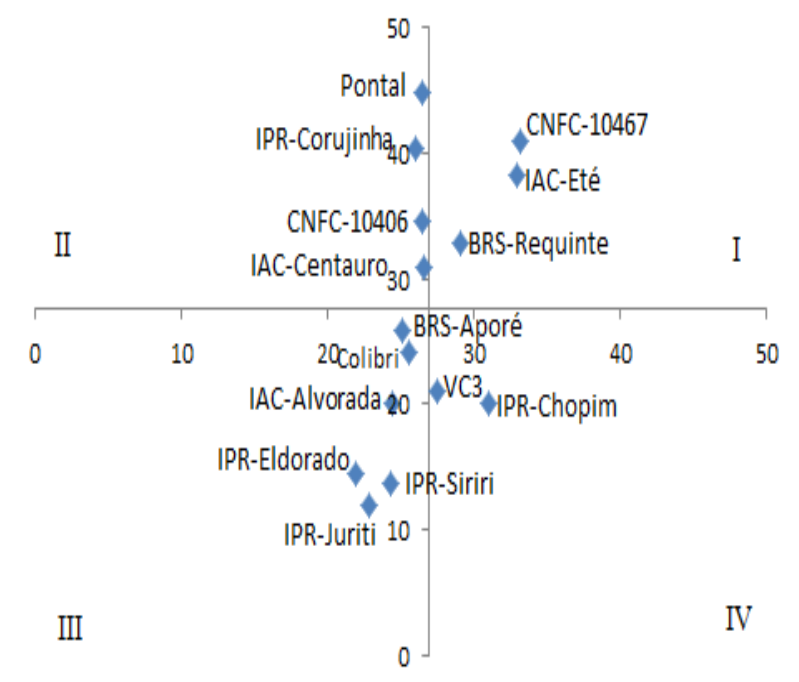

Figura 1. Relação entre comprimento de raiz (cm) em condições de estresse de alumínio $\left(0 \mathrm{mg} \mathrm{L}^{-1} \mathrm{pH} 6,5\right)$ e o índice de redução do comprimento de raiz (\%) de 15 genótipos de feijão comum cultivados em solução nutritiva contendo 0 e 6 $\mathrm{mg} \mathrm{L}^{-1}$ de alumínio.

Na Figura 1 consta o desempenho dos genótipos em relação ao comprimento de raiz quando cultivada em solução nutritiva sem alumínio com pH 6,5 e o índice de redução. O genótipo 10467 apresentou índice de $40,96 \%$ no quadrante I, com alto desenvolvimento radicular, sendo classificado como pouco tolerante à toxidez por alumínio, podendo ser recomendado para cultivos de média e alta tecnologia. No segundo quadrante estão presentes os genótipos Pontal e IPRCorujinha, que obtiveram os maiores índices de redução $(44,93 \%$ e 40,48\%). Esses genótipos apresentaram 
baixo desenvolvimento radicular e foram classificados como pouco tolerantes ao alumínio. Portanto, não são recomendados para cultivo sem as devidas correções do solo. Os cultivares IPR Juriti, IPR Siriri, IPR Eldorado, IAC Alvorada, Colibri, BRS Aporé, IPR Chopim e VC3 destacaram-se por apresentar o índice de redução abaixo da média (quadrante III e IV), sendo classificados como tolerantes com baixo e alto desenvolvimento radicular, respectivamente. A identificação e seleção de cultivares aos elevados níveis de alumínio no solo são desejáveis, permitindo a utilização direta dessas plantas pelos agricultores, reduzindo custos de manejo da cultura, promovendo aumento no rendimento e maiores lucros (Ma, 2007; Carlin et al., 2012).

Tabela 3. Média da característica comprimento radicular (CR) de 15 genótipos de feijão comum cultivados em concentrações diferentes de alumínio a pH 4,0 $\pm 0,2\left(0,3\right.$ e $\left.6 \mathrm{mg} \mathrm{L}^{-1}\right)$ e a pH 6,5 $\pm 0,2 \mathrm{sem}$ alumínio, na região sul do Estado do Tocantins - Gurupi, TO.

\begin{tabular}{|c|c|c|c|c|}
\hline \multirow{3}{*}{ Genótipos } & \multicolumn{4}{|c|}{ Comprimento radicular $\left(\mathrm{cm} \mathrm{planta}^{-1}\right)$} \\
\hline & \multicolumn{3}{|c|}{$\mathrm{pH} 4,0$} & \multirow{2}{*}{$\begin{array}{c}\mathrm{pH} \mathrm{6,5} \\
0 \mathrm{mg} \mathrm{L}^{-1}\end{array}$} \\
\hline & $0 \mathrm{mg} \mathrm{L}^{-1}$ & $3 \mathrm{mg} \mathrm{L}^{-1}$ & $6 \mathrm{mg} \mathrm{L}^{-1}$ & \\
\hline VC3 & $25,34 \mathrm{bcA}$ & $26,10 \mathrm{aA}$ & $21,75 \mathrm{abA}$ & 27,57 abcdA \\
\hline Pontal & $33,00 \mathrm{abA}$ & $23,90 \mathrm{aBC}$ & $18,25 \mathrm{abD}$ & $26,45 \mathrm{abcdB}$ \\
\hline IPR Juriti & $26,50 \mathrm{abcA}$ & $22,92 \mathrm{aA}$ & $20,08 \mathrm{abA}$ & $22,82 \mathrm{cdA}$ \\
\hline IPR Corujinha & $30,82 \mathrm{abcA}$ & $25,70 \mathrm{aA}$ & $15,50 \mathrm{bB}$ & 26,04 abcdA \\
\hline IPR Eldorado & $34,05 \mathrm{aB}$ & $23,75 \mathrm{aA}$ & $18,83 \mathrm{abB}$ & $22,01 \mathrm{~dB}$ \\
\hline Colibri & $28,03 \mathrm{abcA}$ & $27,83 \mathrm{aA}$ & $19,42 \mathrm{abB}$ & $25,62 \mathrm{abcd} A B$ \\
\hline BRS Aporé & 29,58 abcA & $27,08 \mathrm{aA}$ & $18,67 \mathrm{abB}$ & 25,17 abcdAB \\
\hline IPR Siriri & $22,58 \mathrm{cA}$ & $25,58 \mathrm{aA}$ & $21,00 \mathrm{abA}$ & $24,35 \mathrm{cdA}$ \\
\hline IAC Alvorada & $33,82 \mathrm{abB}$ & $24,62 \mathrm{aA}$ & $19,58 \mathrm{abB}$ & $24,50 \mathrm{bcdB}$ \\
\hline CNFC 10406 & $23,28 \mathrm{cAB}$ & $25,95 \mathrm{aA}$ & $17,38 \mathrm{abB}$ & 26,53 abcdA \\
\hline IPR Chopim & $27,70 \mathrm{abcA}$ & $29,52 \mathrm{aA}$ & $24,80 \mathrm{aA}$ & $31,00 \mathrm{abcA}$ \\
\hline IAC Centauro & $25,73 \mathrm{abcA}$ & $24,58 \mathrm{aAB}$ & 18,38 abB & 26,58 abcdA \\
\hline BRS Requinte & $27,57 \mathrm{abcA}$ & $29,08 \mathrm{aA}$ & $19,58 \mathrm{abB}$ & 29,12 abcdA \\
\hline IAC Eté & $26,26 \mathrm{abcB}$ & $23,33 \mathrm{aB}$ & $20,40 \mathrm{abB}$ & $33,00 \mathrm{abA}$ \\
\hline CNFC 10467 & $27,53 \mathrm{abcAB}$ & $25,95 \mathrm{aBC}$ & $19,60 \mathrm{abC}$ & $33,20 \mathrm{aA}$ \\
\hline Média Geral & 28,12 & 25,73 & 19,55 & 26,93 \\
\hline
\end{tabular}

Médias seguidas de mesma letra minúscula na coluna e maiúscula na mesma linha não diferem entre si pelo teste Tukey, a $5 \%$ de probabilidade.

Tabela 4. Média da característica massa seca da parte aérea de 15 genótipos de feijão comum cultivados em concentrações diferentes de alumínio a pH 4,0 $\pm 0,2\left(0,3\right.$ e $\left.6 \mathrm{mg} \mathrm{L}^{-1}\right)$ e a pH 6,5 \pm 0,2 sem alumínio, na região sul do Estado do Tocantins - Gurupi, TO.

\begin{tabular}{|c|c|c|c|c|}
\hline \multirow{3}{*}{ Genótipos } & \multicolumn{4}{|c|}{ Massa Seca da Parte Aérea $\left(\mathrm{g} \mathrm{planta}^{-1}\right)$} \\
\hline & \multicolumn{3}{|c|}{$\mathrm{pH} 4,0$} & \multirow{2}{*}{$\begin{array}{c}\mathrm{pH} \mathrm{6,5} \\
0 \mathrm{mg} \mathrm{L}^{-1}\end{array}$} \\
\hline & $0 \mathrm{mg} \mathrm{L}^{-1}$ & $3 \mathrm{mg} \mathrm{L}^{-1}$ & $6 \mathrm{mg} \mathrm{L}^{-1}$ & \\
\hline VC3 & $0,441 \mathrm{bcA}$ & $0,229 \mathrm{dBC}$ & $0,148 \mathrm{eC}$ & $0,365 \mathrm{bAB}$ \\
\hline Pontal & $0,345 \mathrm{bcA}$ & $0,223 \mathrm{dA}$ & $0,168 \mathrm{de} A$ & $0,319 \mathrm{bA}$ \\
\hline IPR Juriti & $0,373 \mathrm{bcA}$ & $0,289 \mathrm{~cd} A$ & 0,222 cdeA & $0,393 \mathrm{bA}$ \\
\hline IPR Corujinha & $0,552 \mathrm{abA}$ & $0,358 \mathrm{abcdBC}$ & $0,271 \mathrm{bcdeC}$ & $0,471 \mathrm{bAB}$ \\
\hline IPR Eldorado & $0,550 \mathrm{abA}$ & $0,226 \mathrm{dC}$ & 0,270 bcdeBC & $0,409 \mathrm{bAB}$ \\
\hline IPR Colibri & $0,513 \mathrm{bcAB}$ & $0,329 \mathrm{bcdBC}$ & $0,152 \mathrm{eC}$ & $0,438 \mathrm{bA}$ \\
\hline BRS Aporé & $0,473 \mathrm{bcA}$ & 0,369 abcd $A B$ & $0,239 \mathrm{cdeB}$ & $0,476 \mathrm{abA}$ \\
\hline IPR Siriri & $0,432 \mathrm{bcAB}$ & $0,153 \mathrm{dC}$ & 0,260 bcdeBC & $0,441 \mathrm{bA}$ \\
\hline IAC Alvorada & $0,763 \mathrm{aA}$ & $0,446 \mathrm{abcBC}$ & $0,620 \mathrm{aAB}$ & $0,369 \mathrm{bC}$ \\
\hline CNFC 10406 & $0,458 \mathrm{bcA}$ & $0,528 \mathrm{abA}$ & 0,427 abcA & $0,384 \mathrm{bA}$ \\
\hline IPR Chopim & $0,442 \mathrm{bcB}$ & $0,312 \mathrm{bcdB}$ & 0,320 bcdeB & $0,710 \mathrm{aA}$ \\
\hline IAC Centauro & $0,437 \mathrm{bcA}$ & $0,399 \mathrm{abcA}$ & $0,477 \mathrm{abA}$ & $0,463 \mathrm{bA}$ \\
\hline BRS Requinte & $0,434 \mathrm{bcA}$ & $0,581 \mathrm{aA}$ & 0,446 abcA & $0,541 \mathrm{abA}$ \\
\hline IAC Eté & $0,498 \mathrm{bcA}$ & 0,378 abcdA & 0,395 abcdA & $0,469 \mathrm{bA}$ \\
\hline CNFC 10467 & $0,301 \mathrm{cA}$ & 0,332 bcdA & 0,404 abcA & $0,465 \mathrm{bA}$ \\
\hline Média Geral & 0,467 & 0,343 & 0,321 & 0,842 \\
\hline
\end{tabular}


Tabela 5. Média da característica massa seca da raiz de 15 genótipos de feijão comum cultivados em concentrações diferentes de alumínio a pH 4,0 0,2 (0,3 e $\left.6 \mathrm{mg} \mathrm{L}^{-1}\right)$ e a pH 6,5 \pm 0,2 sem alumínio, na região sul do Estado do Tocantins - Gurupi, TO.

\begin{tabular}{|c|c|c|c|c|}
\hline \multirow{3}{*}{ Genótipos } & \multicolumn{4}{|c|}{ Massa Seca da Raiz (g planta ${ }^{-1}$ ) } \\
\hline & \multicolumn{3}{|c|}{$\mathrm{pH} 4,0$} & \multirow{2}{*}{$\begin{array}{r}\text { pH 6,5 } \\
0 \mathrm{mg} \mathrm{L}^{-1}\end{array}$} \\
\hline & $0 \mathrm{mg} \mathrm{L}^{-1}$ & $3 \mathrm{mg} \mathrm{L}^{-1}$ & $6 \mathrm{mg} \mathrm{L}^{-1}$ & \\
\hline VC3 & 0,096 abA & $0,101 \mathrm{abA}$ & $0,123 \mathrm{abA}$ & $0,107 \mathrm{aA}$ \\
\hline Pontal & $0,080 \mathrm{abA}$ & $0,118 \mathrm{abA}$ & $0,076 \mathrm{bA}$ & $0,079 \mathrm{aA}$ \\
\hline IPR Juriti & $0,097 \mathrm{abA}$ & $0,118 \mathrm{abA}$ & $0,124 \mathrm{abA}$ & $0,137 \mathrm{aA}$ \\
\hline IPR Corujinha & $0,144 \mathrm{aA}$ & $0,144 \mathrm{abA}$ & $0,117 \mathrm{abA}$ & $0,116 \mathrm{aA}$ \\
\hline IPR Eldorado & $0,171 \mathrm{aA}$ & $0,130 \mathrm{abA}$ & $0,108 \mathrm{abA}$ & $0,109 \mathrm{aA}$ \\
\hline IPR Colibri & $0,153 \mathrm{aA}$ & $0,106 \mathrm{abA}$ & $0,109 \mathrm{abA}$ & $0,097 \mathrm{aA}$ \\
\hline BRS Aporé & $0,155 \mathrm{aA}$ & $0,124 \mathrm{abA}$ & $0,096 \mathrm{bA}$ & $0,118 \mathrm{aA}$ \\
\hline IPR Siriri & $0,114 \mathrm{abA}$ & $0,110 \mathrm{abA}$ & $0,118 \mathrm{abA}$ & $0,125 \mathrm{aA}$ \\
\hline IAC Alvorada & $0,134 \mathrm{aAB}$ & $0,113 \mathrm{abAB}$ & $0,174 \mathrm{abA}$ & $0,068 \mathrm{aB}$ \\
\hline CNFC 10406 & $0,079 \mathrm{abB}$ & $0,150 \mathrm{abAB}$ & $0,214 \mathrm{aA}$ & $0,081 \mathrm{aB}$ \\
\hline IPR Chopim & $0,074 \mathrm{abC}$ & $0,187 \mathrm{aA}$ & $0,084 \mathrm{bBC}$ & $0,167 \mathrm{aAB}$ \\
\hline IAC Centauro & $0,091 \mathrm{abA}$ & $0,105 \mathrm{abA}$ & $0,126 \mathrm{abA}$ & $0,104 \mathrm{aA}$ \\
\hline BRS Requinte & $0,073 \mathrm{abA}$ & $0,118 \mathrm{abA}$ & $0,103 \mathrm{abA}$ & $0,107 \mathrm{aA}$ \\
\hline IAC Eté & $0,127 \mathrm{aA}$ & $0,098 \mathrm{abA}$ & $0,090 \mathrm{bA}$ & $0,135 \mathrm{aA}$ \\
\hline CNFC 10467 & $0,010 \mathrm{bA}$ & $0,075 \mathrm{bA}$ & $0,088 \mathrm{bA}$ & $0,063 \mathrm{aA}$ \\
\hline Média Geral & 0,107 & 0,120 & 0,117 & 0,107 \\
\hline
\end{tabular}

Médias seguidas de mesma letra minúscula na coluna e maiúscula na mesma linha não diferem entre si pelo teste Tukey, a 5\% de probabilidade.

Os resultados desse estudo mostram que oito dos genótipos avaliados apresentaram tolerância ao alumínio. Portanto, a utilização desses genótipos, por possuírem características agronômicas desejáveis relacionadas à tolerância por alumínio, pode ser uma alternativa econômica viável para a agricultura familiar, uma vez que apresentam um nível tecnológico baixo, além de serem importantes também para programas de melhoramento genético.

\section{Conclusões}

Existe variabilidade genética entre os genótipos de feijão comum quanto à tolerância ao alumínio tóxico.

O genótipo Pontal mostrou-se muito sensível ao alumínio, apresentando baixo comprimento radicular, baixa massa seca radicular, como também massa seca da parte aérea.

Os cultivares IPR Chopim e VC3 foram considerados tolerantes ao alumínio, apresentando bom desenvolvimento radicular.

Os genótipos que se comportaram como tolerantes poderão ser indicados para cultivo em locais onde predominam solos com elevada acidez e com pouca tecnologia.

\section{Referências Bibliográficas}

Brasil. 2015. Ministério da Agricultura, Pecuária e Abastecimento. Projeções do Agronegócio: Brasil 2011/2012 a 2021/2022. Brasília-DF: Mapa/ AGE, 133 p.
Brasil. 2009 Ministério Da Agricultura, Pecuária e Abastecimento. Regras para Análise de Sementes. BrasíliaDF: Mapa/ACS, 395p.

Bresolin, A.P.S., Castro, C.M., Mittelmann, A., Oliveira, A.C., Mistura, C.C., Ahlert, R.J., Farias, D.R., Luz, V.K., Silva, V.N., 2012. Resposta de populações de azevém anual ao alumínio tóxico em condições hidropônicas. Magistra, 24, 332-340.

Cançado, G.M.A., CARNEIRO, N.P., Carneiro, A.A., Purcino, A.A.C., Guimarães, C.T., Alves, M.C., Parentoni, S.N., Souza, I.R.P., Paiva, E., 2001. Novas perspectivas para a adaptação de culturas ao cerrado. Biotecnologia Ciência e desenvolvimento, 4, 56-61.

Carlin, S.D., Rhein, A., Santos, D.M.M., 2012. Efeito simultâneo da eficiência hídrica e do alumínio tóxico no solo na cultivar IAC91-5155 de cana-de-açúcar. Semina: Ciências Agrárias, 33, 553-564.

Conab. Companhia Nacional de Abastecimento. Acompanhamento de safra brasileira de grãos. $3^{\circ}$ levantamento, Brasília-DF: Conab, 2013. Disponível em: $<$ http://www.conab.gov.br/conteudos.php?a=1253\&ordem $=$ produto\&Pagina_objcmsconteudos $=17 \#$ A_objcmsconteudos >. Acesso em: 20 fev. 2017.

Conab. Companhia Nacional de Abastecimento. Acompanhamento de safra brasileira de grãos. $4^{\circ}$ levantamento, Brasília-DF: Conab, 2017. Disponível em: <http://www.conab.gov.br/conteudos.php?a=1253\&t=2>.

Acesso em: 20 fev. 2017.

Ferreira, D.F., 2011. Sisvar: a computer statistical analysis system. Ciência e Agrotecnologia, 35, 15-76.

Freitas, F.A., Kopp, M.M., Sousa, R.O., Zimmer, P.D., Carvalho, F.I.F., Oliveira, A.C., 2006. Absorção de P, Mg, Ca e K e tolerância de genótipos de arroz submetidos a estresse por alumínio em sistemas hidropônicos. Ciência Rural, 36, 7279. 
Hervé, C. B., Calai, F.A., Nava, I.C, Dela Torre, C.A., 2013. Tolerância ao alumínio tóxico em germoplasma brasileiro elite de aveia. Ciência Rural, 43, 1364-1370.

Hoagland, D.R., Arnon, D.I., 1950. The water culture method for growing plants without soil. Berkeley-CA: Agricultural Experimental Station, The collage of Agriculture. p. 1-32. (Circular, 347)

Huang, C.F., Yamaji, N., Nishimura, M., Tajima, S., Ma, J. F., 2009. A bacterial-type $\mathrm{ABC}$ transporter is involved in aluminum tolerance in rice. Plant Cell, 21, 655-667.

Köppen, W., 1948. Climatologia: con un estudio de los climas de la tierra. Fondo de Cultura Econômica. Pachuca, México. $479 \mathrm{p}$.

Lopes Junior, C.O., Amorim, A.C.P., Souza, M.W.S., Silva, V.D.M., Silva, M.R., Silvestre, M.P.C., 2010. Otimização da extração enzimática da proteína do feijão. Acta Scientiarum Technology, 32, 319-325.

Ma, J.F., 2007. Syndrome of aluminium toxicity and diversity os aluminium resistance in higher plants. Internation Review of Cytology, 264, 225-252.

Mattiello, E.M., Pereira, M.G., Zonta, E., Mauri, J., Mattiello, J.D., Merieles, P.G., Silva, I.R., 2008. Produção de matéria seca, crescimento radicular e absorção de cálcio, fósforo e alumínio por Coffea canephora e Coffea arabica sob influência da atividade do alumínio em solução. Revista Brasileira de Ciência do Solo, 32, 425-434.

Martins, C.E., Miguel, P.S.B., Rocha, W.S.D., Sobrinho, F.S., Gomes, F.T., Oliveira, A.V. 2011. Seleção de genótipos de Brachiaria ruziziensis quanto à tolerância ao alumínio em solução nutritiva. Revista de Ciências Agrárias, 34, 154-162.
Miguel, P.S.B., Gomes, F.T., Rocha, W.S.D., Martins, C.E, Carvalho, C. A., Oliveira, A.V., 2010. Efeitos tóxicos do alumínio no crescimento das plantas: mecanismos de tolerância, sintomas, efeitos fisiológicos, bioquímicos e controles genéticos. CES Revista, 24, 12-30.

Nolla, A, Schlindwein, J.A., Anghinoni, I., 2007. Crescimento, morfologia radicular e liberação de compostos orgânicos por plântulas de soja em função da atividade de alumínio na solução do solo de campo natural. Ciência Rural, $37,97-101$.

Parentoni, S.N., Alves, V.M.C., Milach, S.K., Cançado, G.M.A., Bahia Filho, A.F.C.B., 2001. Melhoramento para tolerância ao alumínio como fator de adaptação a solos ácidos. In: Nass, L.L., Valois, A.C.C., Melo, I.S., Valadares-Inglis, M.C. (Eds). Recursos genéticos e Melhoramento, Rondonópolis-MT: Fundação Mato Grosso. p. 783-851.

Peixoto, P.H.P., Pimenta, D.S., Cambraia, J., 2007. Alterações morfológicas e acúmulo de compostos fenólicos em plantas de sorgo sob estresse de alumínio. Bragantia, 66, 17-25.

Sanchez-Chacón, C.D., Federizzi, L.C., Milach, S.C.K., Pacheco, M.T., 2002. Variabilidade genética e herança da tolerância à toxicidade do alumínio em aveia. Pesquisa Agropecuária Brasileira, 35, 1797-1808.

Sharma, A.D., Sharma, H., Lightfoot, D.A., 2011. The genetic control of tolerance to aluminum toxicity in the 'Essex' by 'Forrest' recombinant inbred line population. Theoretical and Applied Genetics, 122, 687-694.

Zeffa, D.M., Sandoli Filho, R., Moda-Cirino, V., Pavan, M.A., 2011. Variabilidade Genética Para Tolerância à Toxidez de Alumínio em Cultivares e Linhagens Promissoras de Feijão. UNOPAR. Científica: Ciências Exatas e Tecnologia, 10, 21-28. 